Revista eletrônica Ludus Scientiae - (RELuS) | V. 2, N. 2, Jul./Dez. 2018.

\section{O JOGO DIDÁTICO “NA TRILHA DOS COMBUSTÍVEIS”: EM FOCO A TERMOQUÍMICA E A ENERGIA}

\author{
The didático game "in the trail of the fuels": in focus the thermochemical and energy
}

El juego didáctico "en la trilla de los combustibles": en foco la termoquímica y la energía
AUTORAS:

FERNANDA WELTER

ADAMS

ORCID 0000-0003-4935-5198

${ }^{1}$ Instituto Federal

Goiano (IFGoiano)

\section{Resumo}

A educação contemporânea exige mudanças que visem dinamizar o processo de ensino/aprendizagem; o desenvolvimento de jogos tem esse propósito, o de tornar as aulas de Química mais atrativas. Com este objetivo, as bolsistas do Programa Institucional de Bolsa de Iniciação à Docência (Pibid) de um Curso de Licenciatura em Química de uma Universidade Pública do Estado de Goiás desenvolveram o jogo didático "Na Trilha dos Combustíveis". O jogo relacionou os conceitos de Termoquímica com o Tema Químico/Social "Poluição x Rendimento Energético" a fim de abordar situações cotidianas. Utilizou-se de uma pesquisa qualitativa, da observação participante e de um questionário para avaliar o impacto do jogo no processo de ensino/aprendizagem. Através da análise dos dados percebeu-se que o jogo permitiu que os alunos se divertissem e construíssem conhecimento, equilibrando as funções lúdica e pedagógica. A partir do jogo o aluno é motivado a entender a Química, sua importância e a buscar o conhecimento de forma autônoma, crítica e prazerosa.

Palavras-Chave: Tema Químico/Social, Apropriação de conhecimento, Lúdico.

\begin{abstract}
The contemporary education requires changes that aimed to boost the process of teaching/learning; the development of didactic games intend become chemistry lessons more attractive. With this aim, the scholarship holders of the Institutional Program of Iniciation to Teaching Scholarships - Pibid - of a Chemistry Course at a Public University in Goiás developed the didactic game "In the trail of the fuels". The didactic game related the concepts of Thermochemistry with the chemical/social theme "Pollution x Energy Efficiency", approaching people's daily situations. It was used a qualitative research, developed through participant observation and questionnaires to assess the impact of the didactic game on teaching/learning process. Through the analysis of the collected data, it was revealed that the didactic game "On the Track of the Energetic Sustainability" allowed students to have fun and build knowledge, balancing recreational and educational functions. Through didactic game, the student is motivated to understand Chemistry, its importance and to seek knowledge independently, critically and pleasurably.
\end{abstract}

Keywords: Knowledge construction; Didactic games; Thermochemistry.

\section{Resumen}

La educación contemporánea exige cambios que visen dinamizar el proceso de enseñanza / aprendizaje; el desarrollo de juegos tiene ese propósito, el de hacer las clases de Química más atractivas. Con este objetivo, las becas del Programa Institucional de Beca de Iniciación a la Docencia (Pibid) de un Curso de Licenciatura en Química de una Universidad Pública del Estado de Goiás desarrollaron el juego didáctico "En la trilla de los combustibles". El juego relacionó los conceptos de Termoquímica con el Tema Químico / Social "Polución x Rendimiento Energético" a fin de abordar situaciones cotidianas. Se utilizó una encuesta cualitativa, la observación participante y un cuestionario para evaluar el impacto del juego en el proceso de enseñanza / aprendizaje. A través del análisis de los datos se percibió que el juego permitió que los alumnos se divertían y construyesen conocimiento, equilibrando las funciones lúdica y pedagógica. A partir del juego el alumno es motivado a entender la química, su importancia ya buscar el conocimiento de forma autónoma, crítica y placentera.

Palabras clave: Construcción de conocimiento; Juego didáctico; Termoquímica.
SIMARA MARIA TAVARES

NUNES $^{2}$

ORCID 0000-0002-7196-4398

Universidade Federal de Goiás (UFG)

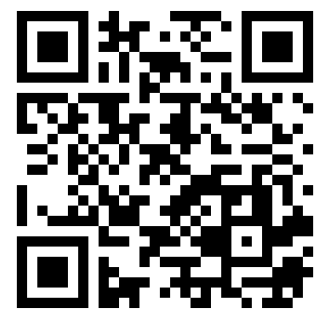

Para citar este artigo:

ADAMS, F. W.; NUNES, S. M. T. O jogo didático "na trilha dos combustíveis": em foco a termoquímica e a energia. Revista Eletrônica Ludus Scientiae, Foz do Iguaçu, v. 02, n. 02, p. 90-105, jul./dez. 2018. 


\section{INTRODUÇÃO}

No Ensino tradicional de Química o indivíduo interage com um conhecimento essencialmente acadêmico e propedêutico, principalmente através da transmissão e recepção de informações/conteúdos. Neste, supõe-se que o estudante, memorizando informações passivamente, adquira o "conhecimento historicamente acumulado" (BRASIL, 1999), ou seja, desta forma o ensino de Química é apresentado dicotomizado da realidade dos educandos.

Entende-se que para superar o ensino tradicional é necessário adotar uma postura que valorize a apropriação de conhecimentos pelo aluno, ou seja, há a necessidade de se adotar metodologias e recursos didáticos que possibilitem ensinar a Química de forma mais dinâmica e interativa para que esta atinja o objetivo de formar cidadãos conscientes, críticos e participativos na sociedade.

Nóvoa (1997) defende que: a mudança educacional depende da transformação da prática pedagógica em sala de aula. Soares (2003) por sua vez, afirma que estratégias modernas e simples como os jogos educativos são recomendados para dinamizar o processo de ensino e aprendizagem de Química, pois as atividades lúdicas promovem o aprendizado com prazer.

Assim, acredita-se que os jogos sejam um caminho para se promover mudanças na prática pedagógica e para se desenvolver conhecimentos, como disposto nos documentos que regem as propostas atuais de Educação para o Ensino Médio como a LDBEN (Lei de Diretrizes e Bases da Educação Nacional) (BRASIL, 1996), os PCNEN (Parâmetros Curriculares Nacionais do Ensino Médio) (BRASIL, 1999) e os PCN+ (Orientações Educacionais Complementares aos Parâmetros Curriculares Nacionais) (BRASIL, 2002). Destaca-se que durante o jogo didático o educando é estimulado/motivado a explorar e resolver problemas; desta forma, torna-se sujeito ativo na construção do seu conhecimento. Grando (1995, p 77) endossa a ideia de que a construção de conhecimentos através do jogo pode ser proporcionada pela resolução de problemas, motivando o aluno para o aprendizado:

O jogo e a resolução de problemas se apresentam impregnados de conteúdo em ação e que, psicologicamente, envolvem o pensar, o estruturar-se cognitivamente a partir do conflito gerado pela situação-problema. A ação no jogo, tanto quanto no problema, envolve um objetivo único que é vencer o jogo ou resolver o problema e, em ambos os casos, o estudante se sente desafiado e motivado a cumprir esse objetivo. Atingir o objetivo implica em dominar, em conhecer, em compreender todos os aspectos envolvidos na ação e, portanto, produzir conhecimento (GRANDO, 1995, p. 77).

Outro benefício do jogo está na possibilidade de se estimular a exploração em busca de respostas e em não se constranger quando se erra. Segundo Vygotsky (1989) o erro também permite um processo de ensino e aprendizagem e ainda pode ser usado para estimular o pensamento reflexivo do educando; assim este tem a oportunidade de construir conhecimento de forma efetiva. Já para Valente (2005) os jogos didáticos são mais do que simples exercícios; oportunizam ao aluno aprender a ser crítico e confiante em si mesmo; não apenas a pensar, mas incentiva ainda a troca de ideias, contribuindo para o desenvolvimento da autonomia.

Para Fialho (2008) por meio da atividade lúdica o professor pode colaborar com a elaboração de conceitos, promover a socialização entre os alunos e trabalhar a criatividade, o espírito de competição e a cooperação.

O professor pode ainda avaliar o conhecimento do educando através do jogo didático. Mas não avaliar se o educando memorizou o conceito químico e sim se ele (re)construiu conhecimento efetivo. A avaliação exige uma observação sistemática dos alunos não apenas com relação ao domínio de conceitos de conteúdos específicos, mas também com relação ao desenvolvimento de conhecimentos, valores e atitudes como a tomada de decisão, capacidade de comunicar-se, trabalho em equipe, capacidade de pesquisar, investigar e compreender informações, capacidade de argumentar e de ser autônomo, capacidade de cooperação, socialização e organização, responsabilidade e a participação ativa dos educandos na sociedade. Estes conhecimentos se relacionam tanto no campo cognitivo quanto no campo afetivo e ético do educando. 
O jogo didático permite ainda que o professor assuma o papel de mediador do conhecimento. Assim, o docente constituiu um fator essencial para que o jogo didático atinja seu objetivo; dentre suas funções pode-se ressaltar a criação de situações de estímulo e a promoção da aprendizagem dos educandos. Segundo os PCN's + (Orientações Educacionais Complementares aos Parâmetros Curriculares Nacionais) (BRASIL, 2002, p. 28):

[...] cabe ao professor selecionar, organizar e problematizar os conceitos de modo a possibilitar o avanço intelectual do aluno [...], cabe ao professor ainda a tarefa de organizar a atividade e propor regras e fazer com que estas sejam cumpridas pelos educandos.

Segundo a atual Legislação Educacional Brasileira, o Ensino Médio, etapa final da educação básica, tem a finalidade de promover a construção de um conhecimento efetivo e também de desenvolver conhecimentos diversos que não só os cognitivos que preparem os alunos para a vida em sociedade.

E a melhor forma do aluno conhecer a realidade e ter a capacidade de mudá-la é se rever o currículo e adequá-lo às novas exigências, priorizando valores ideológicos, morais, éticos e ambientais e consequentemente as relações interpessoais dos alunos com a sociedade, através de uma formação ética e o desenvolvimento de autonomia intelectual e do pensamento crítico. E, a inserção da temática sustentabilidade energética no ensino básico contribui para que os alunos adquiram a criticidade e a criatividade para se tornarem cidadãos ativos na sociedade em que vivem. A sustentabilidade, em especial à sustentabilidade energética, é um tema atual e necessário de ser trabalhado (no âmbito da Química em particular) com o objetivo de conscientizar os alunos da importância que a preservação ambiental tem perante a sobrevivência da sociedade.

Os hábitos de uma sociedade estão ligados a sua cultura e a educação é capaz de promover mudanças na cultura; isto ocorre através da inserção de novos valores sociais, pois a sustentabilidade energética é um ideal sistemático que se perfaz principalmente pela ação e pela constante busca entre o desenvolvimento econômico e ao mesmo tempo a preservação do ecossistema. Ou seja, a educação deve ser capaz de promover a motivação de agir em favor da sobrevivência do planeta.

Neste contexto, o presente trabalho busca refletir sobre a seguinte questão o jogo didático "Na Trilha dos combustíveis" foi capaz permitir a construção e (re)construção de aprendizado frente aos conceitos de termoquímica e energia? Para tanto será apresentado o relato da elaboração, do desenvolvimento e da avaliação do jogo didático. Este artigo permite ainda, a reflexão do jogo didático como um recurso facilitador dos processos de ensino e aprendizagem; buscou-se ainda reconhecer se a utilização do jogo se constitui em uma estratégia didática que possibilita recordar e (re)construir o conhecimento e promover a formação de cidadãos críticos/reflexivos, com a capacidade de atuação ativa na sociedade.

\section{METODOLOGIA}

Com o propósito de promover a apropriação de um conhecimento efetivo com educandos do Ensino Médio de escola pública parceira, as bolsistas do Programa Institucional de Bolsa de Iniciação à Docência (Pibid) do Curso de Licenciatura em Química da Universidade Federal de Goiás/Regional Catalão (UFG/RC) propuseram o desenvolvimento de um Projeto Temático denominado "Química e Energia em prol de um desenvolvimento sustentável". Este projeto buscou romper as práticas conteudistas baseadas na transmissão e recepção de conhecimento, buscando trabalhar conteúdos que fossem cientificamente e culturalmente expressivos para os educandos. Uma das atividades propostas neste projeto foi a elaboração e o desenvolvimento de recursos didáticos de cunho lúdico, como os jogos didáticos, de forma a dinamizar o Ensino de Química e garantir o aprendizado.

Para o desenvolvimento deste Projeto Temático as pibidianas, além de jogos didáticos, elaboraram aulas contextualizadas; acredita-se que através da contextualização o educando é levado a fazer uma ponte entre a teoria e a prática, aproximando a escola do mundo real. As aulas elaboradas foram: 
1o Sensibilização (introdução da temática) (6 aulas de 50 minutos cada ): teve por objetivo introduzir a problemática "Energia e Sustentabilidade" chamando a atenção dos alunos para situações cotidianas que tem sido influenciadas pelo mau uso dos recursos energéticos ou pela escassez dos mesmos. Nestas aulas discutiu-se com os alunos a importância da energia e ações que visam suprir as necessidades atuais dos seres humanos sem comprometer o futuro das próximas gerações.

2o Aulas de conceitos químicos contextualizados com a problemática, qual seja, sustentabilidade energética ( 20 aulas minutos cada): estas aulas relacionaram a temática "Combustíveis e Impactos Ambientais" com os conceitos químicos de Termoquímica a fim de problematizar o conhecimento. Ou seja, discutiu-se com os alunos o que são combustíveis, quais os tipos de combustíveis (combustíveis fósseis e combustíveis renováveis) e conceitos químicos relacionados como a variação de entalpia que nos permite verificar a quantidade de energia e os gases poluentes que são liberados pela reação de combustão sofrida pelos combustíveis.

Vale ressaltar que o objetivo das aulas de conceitos químicos contextualizados era apresentar aos alunos os diferentes tipos de combustíveis, associar o uso dos mesmos com a energia e a poluição liberada a partir da reação de combustão de cada um e assim incentivar os alunos a refletirem e escolherem qual o melhor combustível, o que libera mais energia, mas também polui mais o meio ambiente (gasolina) ou o que libera menos energia, mas favorece a sustentabilidade energética poluindo menos o meio ambiente (etanol).

Após as aulas contextualizadas que discutiram todo o conhecimento químico relacionado a termoquímica, bem como as questões relacionadas a sustentabilidade energética enfatizando o uso de energias renováveis, as pibidianas elaboraram, confeccionaram e aplicaram o jogo didático denominado "Na Trilha dos Combustíveis", um jogo de tabuleiro. Destaca-se que para este jogo, optouse por enfatizar o uso dos combustíveis, uma vez que eles foram o ponto de partida para a discussão da sustentabilidade energética. Este foi aplicado em duas turmas do segundo ano do Ensino Médio, com um total de 44 alunos.

O jogo era composto por um tabuleiro (Figura 1), que foi confeccionado em plotter com $70 c m x 60 c m$ de dimensão.

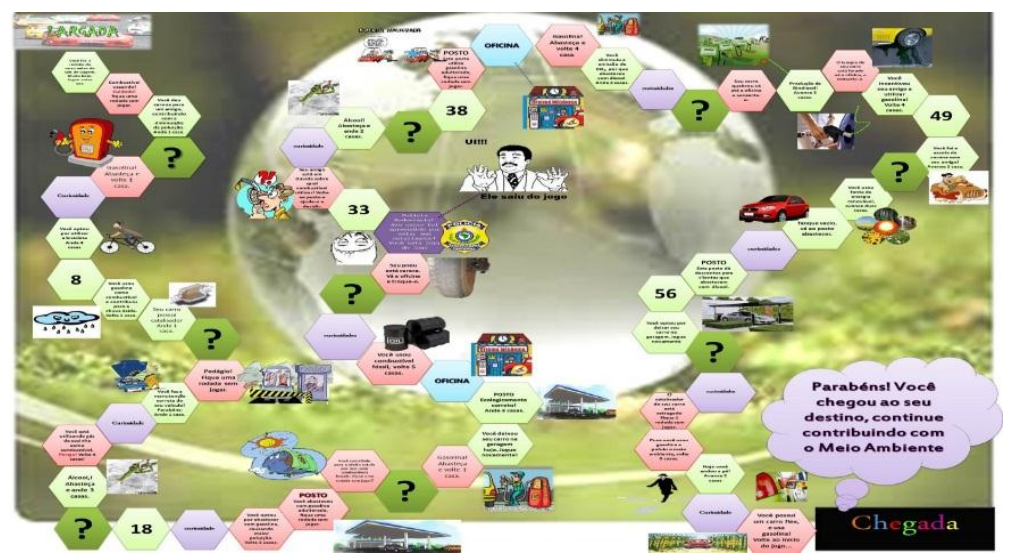

Figura 1: Tabuleiro do jogo didático "Na Trilha dos Combustíveis". Fonte: Elaborada pelas autoras.

Este possuía ainda cartas, sendo 50 Cartas de Perguntas (exemplos na Figura 2) e 27 Cartas de Curiosidades (exemplos na Figura 3), confeccionadas em papel vergê e plastificadas em papel contact; 6 carrinhos de plástico e dados: 

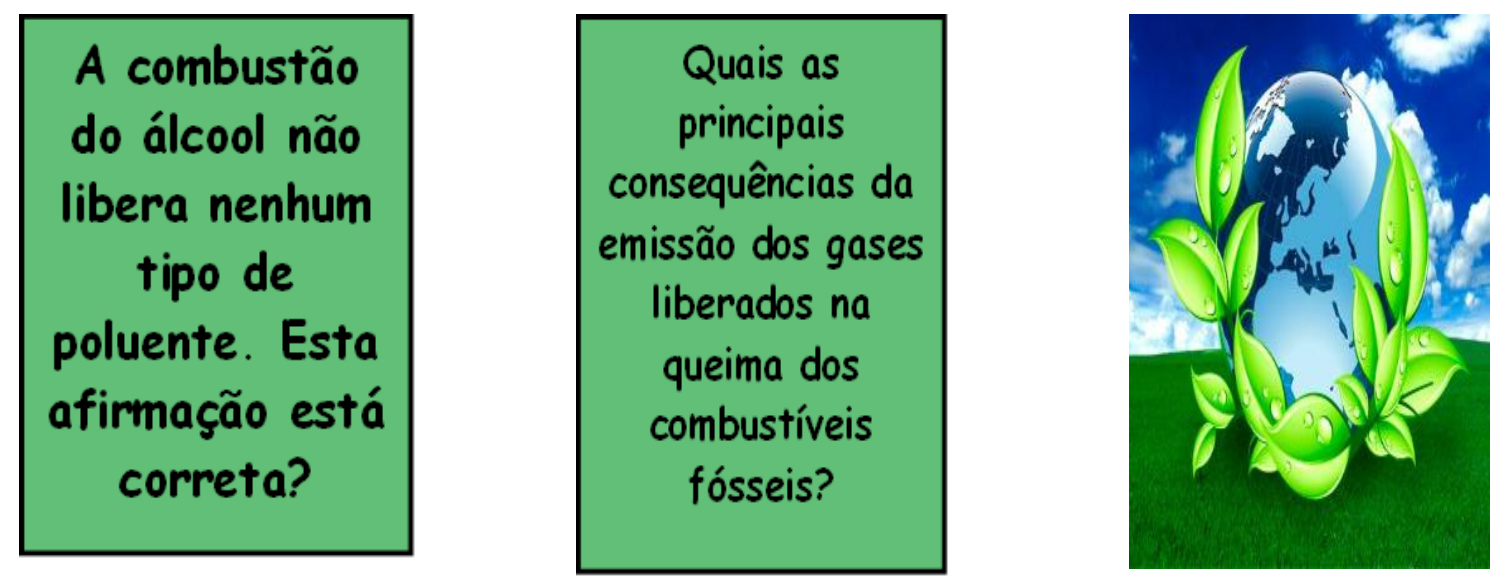

Figura 2: Exemplos de Frente e Verso das Cartas de Perguntas do jogo didático "Na Trilha dos Combustíveis". Fonte: Elaborada pelas autoras.
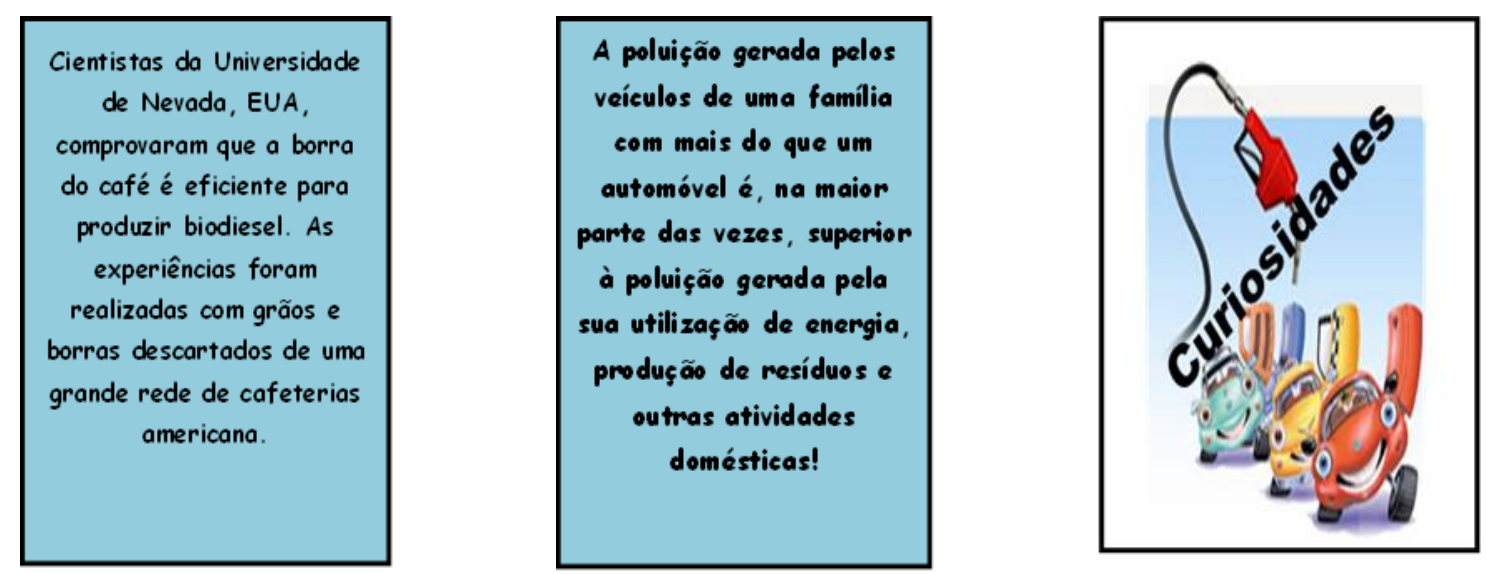

Figura 3: Exemplos de Frente e Verso das Cartas de Curiosidades do jogo didático "Na Trilha dos Combustíveis". Fonte: Elaborada pelas autoras.

A atividade em questão buscou complementar as discussões sobre qual o combustível que favorece a sustentabilidade (energética) e teve ainda o objetivo de sistematizar e formalizar o conhecimento discutido durante o desenvolvimento do Projeto Temático "Química e Energia em prol de um desenvolvimento sustentável". O objetivo do jogo era que o educando chegasse ao final de uma trilha refletindo sobre a sustentabilidade. Enfim, o jogo buscou propiciar o aprendizado e, de certa forma, avaliar se os educandos compreenderam os conteúdos químico/sociais discutidos nas aulas previamente ministradas, pois para a participação na atividade era necessário que o educando tivesse domínio sobre os mesmos a fim de chegar ao seu destino final (fim da trilha).

Com este jogo avaliou-se principalmente se os educandos adquiriram conhecimentos relacionados à tomada de decisão, a capacidade de ser autônomo, a capacidade de comunicar-se e argumentar (pois o aluno deveria defender e expor a sua opinião durante o jogo), a capacidade de cooperação, socialização, organização, a responsabilidade e a participação ativa na sociedade e na apropriação de conhecimento. Vale destacar que o desenvolvimento destes conhecimentos foi avaliado pela observação e também através da análise de um questionário aplicado ao final da atividade (pesquisa qualitativa).

A atividade foi desenvolvida da seguinte forma:

1o momento: a sala foi dividida em grupos de 4 alunos;

2- momento: cada jogador recebeu um carrinho e cada grupo recebeu um tabuleiro e dados;

3 - momento: cada jogador lançou o dado e aquele que tirou o maior número iniciou a partida e a sequência de jogadores seguiu o sentido horário. 
O jogo didático possuía diversas casas coloridas onde as:

Casas verde-escuro: correspondiam às perguntas. Ou seja, se o jogador, durante o percurso, caísse em uma destas casas, deveria retirar do monte de perguntas uma carta contendo uma questão referente ao conteúdo químico/social e respondê-la. Por exemplo, se ao iniciar o jogo um aluno lançou o dado e saiu com o número quatro, ao andar as quatro casas o mesmo cairia em uma casa verde escuro e assim deveria tirar do monte uma carta de pergunta, ler a mesma em voz alta e respondê-la para os demais colegas. Estes julgariam se a resposta estava correta e, se estivesse, o jogador continuaria jogando, ou seja, lançaria novamente o dado. Se não respondesse corretamente ficaria uma rodada sem jogar.

Casas vermelhas: continham informações sobre os malefícios causados pelos combustíveis (aspectos negativos relacionados ao consumo de combustíveis fósseis, como a relação do uso de combustível fóssil com o aumento do efeito estufa, pois o mesmo libera ao meio ambiente mais dióxido de carbono $\mathrm{CO}_{2}$ de origem fóssil) e problemas mecânicos dos automóveis como o vazamento de combustível, o uso de pneus carecas e a falta de catalisador. Se o jogador caísse em alguma destas casas deveria ficar uma rodada sem jogar ou voltar uma, duas, quatro ou cinco casas de acordo com as especificações das mesmas; ou ainda poderia voltar ao início do jogo.

Casas roxas: eram referentes às curiosidades sobre a temática (Cartas de Curiosidades, exemplos na Figura 3). Quando o jogador caísse em uma destas casas deveria ir ao monte de cartas referentes às curiosidades e retirar uma e ler a mesma em voz alta para os demais colegas. Estas curiosidades eram referentes a história dos automóveis e combustíveis. Por exemplo, uma das cartas trazia informações sobre o primeiro automóvel, sua velocidade máxima e a quantidade em massa que um litro de gasolina pode produzir de dióxido de carbono $\left(\mathrm{CO}_{2}\right)$.

Casas azuis: referiam-se às paradas para oficina; se o jogador lançasse o dado e caísse em uma destas casas deveria apenas esperar a sua vez de jogar novamente.

Casas verde-claras: referiam-se às formas sustentáveis de se utilizar os combustíveis, por exemplo, dar carona a um colega de trabalho, fazer uso da bicicleta, etc. Se o jogador caísse em uma destas casas ele poderia jogar outra vez, ou avançar uma, duas, três ou quatro casas de acordo com as instruções de cada casa.

Casa roxo escuro: referente à polícia Federal; se o jogador caísse nela o seu veículo seria apreendido por estar sem catalisador e como consequência o jogador ficaria uma rodada sem jogar.

Para se avaliar o jogo didático "Na Trilha dos Combustíveis" utilizou-se de uma pesquisa de caráter qualitativo; esta última se caracterizou por ter o ambiente natural como fonte de dados descritivos e por considerar os diferentes pontos de vista dos participantes (GODOY, 1995). Utilizouse como instrumento de coleta de dados questionários elaborados com o objetivo de se investigar a aceitabilidade do jogo como um recurso didático diferenciado e que contribui para o processo de ensino/aprendizagem. Segundo Chaer (2011), os questionários possuem uma série de vantagens, sendo de baixo custo, acessíveis, garantem o anonimato e possuem questões objetivas e de fácil tratamento. A observação participante, que não é a contemplação passiva, pois é observando situações que reconhecemos as pessoas e emitimos juízos sobre elas (LAVILLE e DIONNE, 1999), também foi uma ferramenta utilizada para a coleta de dados.

O instrumento de construção de dados foi um questionário aplicado aos alunos que visou investigar se o jogo didático "Na trilha dos Combustíveis" contribuiu para o processo de ensino e aprendizagem dos alunos, possibilitando aos mesmos avaliar o conhecimento apropriado e ainda se este contribuiu para a formação crítico/reflexivo dos alunos. O instrumento possuía questões abertas, na qual os alunos tiveram a liberdade de usar suas próprias palavras para expressar a sua opinião sobre o jogo. Vale destacar que o questionário aplicado foi construído durante reuniões periódicas com a professora supervisora e orientadora do programa Pibid. Nelas, foi possível elaborar e selecionar as perguntas que constariam no questionário e se a partir das mesmas seria possível abstrair as informações necessárias para investigar se o recurso desenvolvido contribuiu para o processo de 
(re)construção do conhecimento químico/social mediado. Para discussão dos resultados e para resguardar a identidade dos educandos eles foram identificados por símbolos de Aı a A44.

Para o tratamento dos dados foi utilizada a Análise Textual Discursiva (MORAES, 2007) pela qual as respostas dos alunos foram agrupadas em unidades de significados. Este tipo de abordagem corresponde a uma análise qualitativa de dados que se inicia com a denominada unitarização dos textos, que os fragmenta em unidades de significado. Após a unitarização, realiza-se o processo de categorização que consiste em agrupar as unidades de significados semelhantes em categorias. E por último, na etapa de comunicação, são elaborados metatextos explicitando as concepções surgidas a partir das informações em combinação com os referenciais teóricos.

Assim, nos tópicos seguintes serão apresentadas as categorias elencadas através análise dos questionários sendo elas:

1o categoria: avaliação do jogo através da observação participante;

2o categoria: a construção de conhecimento através do jogo didático;

3 categoria: a aceitabilidade do jogo e as funções lúdica e educativa;

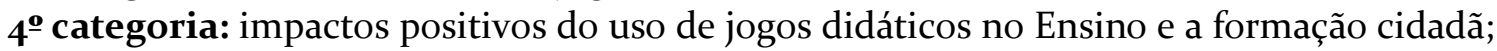

$5^{\circ}$ categoria: os jogos didáticos e a formação inicial docente.

De acordo com Almeida (1998) uma boa aprendizagem exige a participação ativa do aluno, de modo a construir e reconstruir o seu próprio conhecimento. Assim, visando promover o aprendizado de forma ativa e crítica, além de promover a construção de conhecimentos cognitivos e outros que promovam uma participação cidadã dos educandos na sociedade, as bolsistas do subprojeto Pibid/Química/UFG/RC desenvolveram o projeto temático "Química e Energia em Prol de um Desenvolvimento Sustentável”. Dentre as atividades desenvolvidas no decorrer do Projeto destaca-se a elaboração/desenvolvimento/aplicação/avaliação do jogo didático "Na Trilha dos Combustíveis". Este trabalho buscou avaliar o impacto deste jogo didático no processo de ensino/aprendizagem dos alunos.

A partir das definições de Soares (2013) mescladas com as ideias de Legrand (1974) podemos classificar o jogo desenvolvido como sendo de nível de interação II. Os jogos podem ser classificados conforme seus diferentes graus de interação com o sujeito ou com quem os manuseia. O nível de interação II apresenta as seguintes características: "utilização de atividades lúdicas nas quais se primará pelo jogo na forma de competição entre vários estudantes, com um objetivo comum a todos, podendo ou não ser realizada em grupos, sendo geralmente jogos de cartas e tabuleiros" (SOARES, 2013, p.63).

Portanto, o jogo didático "Na Trilha dos Combustíveis" se caracterizou por ser um jogo de tabuleiro que partiu de conceitos químicos associados a conceitos sociais que já haviam sido trabalhados em sala de aula. Sendo assim, durante o desenvolvimento do jogo didático o aluno pôde redescobrir/reconstruir os conceitos que já haviam sido trabalhados anteriormente em sala de aula, porém agora de forma lúdica e prazerosa.

\section{RESULTADOS E DISCUSSÕES}

Tem-se vivenciado profundas mudanças no mundo contemporâneo; essas mudanças influenciam no modo de pensar, agir e falar da sociedade. A educação também é afetada por tantas mudanças, pois se não houver a adequação desta ao mundo globalizado o educando não se motivará para o aprendizado. É preciso que se proporcione a renovação das metodologias de ensino e a diversificação dos recursos didáticos de modo a se estimular os educandos para interagir socialmente $\mathrm{e}$ garantir seu desenvolvimento. Para essa modificação pedagógica é importante que os futuros professores vivenciem essas novas metodologias e recursos didáticos ainda durante sua formação inicial.

O Programa Institucional de Bolsa de Iniciação à Docência do Curso de Licenciatura em Química da Universidade Federal de Goiás - Regional Catalão (Pibid/Química/UFG/RC) tem como um de seus objetivos a promoção de uma formação docente diferenciada, propondo a elaboração, desenvolvimento e aplicação de metodologias e recursos didáticos diversificados e inovadores na 
escola, que busquem contribuir para a melhoria da qualidade dos processos de ensino/aprendizagem, visando apresentar aos alunos a importância da Química para se entender o mundo e, principalmente, apresentar a Química da sua vida cotidiana.

Muitas vezes a Química é apontada como abstrata (pelos educandos) e por isso considerada, também, uma disciplina difícil de ser compreendida, o que acaba desmotivando os alunos para o aprendizado. Por isso é importante trazer para a sala de aula recursos didáticos diferenciados como, por exemplo, os jogos didáticos, que estimulam o interesse dos educandos e os motivam para o aprendizado.

Segundo Cavalcanti e Soares (2009) o uso de jogos didáticos para abordar conceitos químicos surge como alternativa para minimizar dificuldades como a desmotivação pelo aprendizado, pois o jogo pode atribuir sentido a partir de uma atividade que envolve diversão e simulação do real. Ou seja, inserir a ludicidade no Ensino de Química pode despertar o interesse e a participação dos alunos nas aulas e, como consequência, aumentar a motivação do educando para o aprendizado e promover ainda a construção de conhecimentos importantes para a formação cidadã dos educandos.

Assim, após as aulas contextualizadas trabalhou-se o jogo didático "Na Trilha dos Combustíveis" com 44 (quarenta e quatro) alunos do $2^{\circ}$ ano do Ensino Médio de uma escola pública da cidade de Catalão/GO. Os discentes tinham idades entre 15 e 19 anos e a maioria era do sexo feminino (66\%). Dessa forma, segue-se a discussão das categorias levantadas.

\section{Avaliação do jogo através da observação participante}

O jogo foi avaliado inicialmente pela observação participante das pibidianas; a apreciação dos alunos jogando permitiu que estas avaliassem o seu comportamento durante a atividade. Observou-se uma maior motivação dos alunos em buscar o conhecimento a partir do jogo "Na Trilha dos Combustíveis" e que os alunos demonstravam prazer durante a atividade. Ou seja, percebeu-se por meio das falas e das discussões nos momentos de reponderem as questões no decorrer do jogo didático que os alunos aprenderam e se divertiram ao mesmo tempo.

As pibidianas ainda observaram que o jogo didático elaborado permitiu a (re)construção do conhecimento químico/social que já havia sido trabalhado durante as aulas ministradas como o conceito de reação de combustão, qual combustível polui mais e qual gera mais energia e como a Química está envolvida tanto com a poluição quanto com a geração de energia por um combustível. Isto pode ser observado, nos momentos em que alguns alunos caiam nas casas de perguntas e as respondiam erroneamente, os demais alunos promoviam discussões a apresentavam a este aluno a resposta correta, ou seja, o aluno que errou a pergunta tinha a oportunidade de re(construir) seu conhecimento.

Observou-se também que o jogo permitiu uma maior interação entre os alunos que discutiam as questões/respostas do jogo. Ou seja, os alunos puderam aprender a expressar a sua opinião de forma clara e segura e principalmente a aceitar a opinião dos colegas, o que permite que os alunos aprendam a conviver em sociedade. Portanto, a atividade permitiu que o aluno desenvolvesse a capacidade de trabalhar em grupo. O jogo também favoreceu a relação aluno/professor/pibidianas, permitindo a quebra da ideia de que o professor é o detentor do conhecimento e o aluno é apenas um receptor. Ou seja, o jogo permitiu que os alunos discutissem o conteúdo com as pibidianas apresentando assim as suas dúvidas sobre o mesmo, permitindo assim uma melhora no processo de ensino/aprendizagem. Permitiu ainda que laços de amizade fossem criados, o que se acredita que favoreça o interesse dos alunos pela disciplina de Química. Pois a todo o momento o professor/pibidianas ficaram próximas aos grupos tirando dúvidas, laçando novas perguntas, dando dicas, enfim, ajudando os alunos a organizarem o seu pensamento e ainda anotando inquietações e erros dos alunos, para realizar uma síntese do conteúdo trabalho no final da atividade, o que não havia ocorrido tão eficientemente durante as aulas expositivo-dialogadas, pois durante a atividade professor e aluno se divertirem e aprenderem em parceria. 
Percebeu-se também que o professor tem papel importante neste processo de construção de conhecimento; ele deve ser o mediador do conhecimento, dando suporte para o desenvolvimento do educando. Durante a aplicação de um jogo didático o papel mediador do professor se intensifica, pois a mediação deve favorecer o surgimento de condições para que os educandos assumam o centro da atividade lúdico/educativa. Cabe ao professor explicitar as regras do jogo e, conduzi-lo para que o mesmo atinja seus objetivos e cumpra a sua função através do diálogo educativo. Rizzo (2001) afirma que é função do professor instigar a tomada de decisão entre os alunos (jogadores) e a criação de argumentos que defendam do seu ponto de vista sobre o assunto discutido. Assim, acredita-se que as discussões que são promovidas pelo jogo são extremamente importantes para a construção de conceitos científicos e sociais.

Pôde-se observar ainda que o jogo permitiu que os alunos reforçassem a descoberta da realidade (poluição causada pelo uso de combustíveis fósseis e não fósseis) e os problemas causados por essa poluição) e o questionamento (reflexão) de qual o melhor combustível para contribuir com a Sustentabilidade. Enfim, observou-se a formação de cidadãos comprometidos e preocupados com a sustentabilidade do planeta.

Através das observações realizadas percebeu-se, o desenvolvimento dos alunos durante os questionamentos realizados, pois eles buscavam desenvolver a resposta para avançar no jogo. Como o jogo é uma atividade descontraída o educando acaba aprendendo e também desenvolvendo o seu lado social. Assim, acredita-se que ao se atribuir caráter lúdico à aprendizagem pôde-se despertar no aluno o interesse de participar ativamente da apropriação do seu aprendizado e com isso desenvolver aspectos como a atenção, a inteligência e a personalidade, já que o lúdico está ligada ao desenvolvimento do indivíduo.

\section{A construção de conhecimento através do jogo didático}

Avaliou-se a atividade também por meio de um questionário que foi aplicado após o encerramento da atividade. Este visou investigar a aceitação do jogo e ainda se este se constituiu em uma atividade lúdica que contribuiu para que os alunos diferenciassem e compreendessem os diferentes tipos de combustíveis estudados e compreendessem ainda os seus benefícios e malefícios.

Através dos dados coletados por meio da observação e dos questionários pôde-se perceber que o desenvolvimento do jogo contribuiu para o desenvolvimento da:

- $\quad$ A curiosidade de pensar múltiplas alternativas para a solução de um problema: (durante o jogo o aluno era questionado todo tempo; ele deveria procurar resolver o problema (questionamento) da melhor forma possível para avançar no jogo e se consagrar campeão);

- $\quad$ A capacidade de trabalhar em equipe (o jogo exigiu uma interação aluno/aluno);

- A disposição de procurar e aceitar críticas (como o jogo didático "Na dos Combustíveis" é um jogo de grupo os alunos vão discutir, por exemplo, uma resposta de um jogador e assim poderão chegar a uma resposta aceitável);

- $\quad$ O saber comunicar-se (a comunicação é importante para que os alunos possuam argumentos para a defesa de suas opiniões durante os questionamentos do jogo);

- A capacidade de buscar conhecimento (o jogo didático permite que os alunos procurem a resposta de um questionamento; quando os jogadores entre si não chegavam a uma resposta aceitável procuravam a professora ou as pibidianas, que foram mediadoras da resposta e, a partir das discussões, auxiliaram o grupo a propor uma resposta).

Pôde-se perceber assim que variados conhecimentos foram desenvolvidos, o que é de suma importância para garantir a viabilidade do mesmo como um recurso didático que facilita e enriquece o processo de ensino e aprendizagem. 
A fim de estimular o aprendizado buscou-se colocar o educando em contato direto com um problema que está presente em seu cotidiano ao trabalhar com a poluição causada pelos combustíveis. O jogo trouxe duas opções de combustíveis (etanol ou gasolina) para os alunos utilizarem em seus veículos; eles deveriam escolher entre as opções disponíveis aquele que mais favorece a sustentabilidade, sendo o etanol, que libera uma quantidade de $\mathrm{CO}_{2}$ atmosfera, sendo este consumido pela cana durante seu crescimento, mas foi apresentado aos alunos durante as aulas contextualizadas desenvolvidas as desvantagens da produção deste combustível, como que a cultura da cana necessita de desmatamento de grandes áreas, modifica o albedo local, areniza rapidamente os solos, causando impactos ambientais além dos produzidos na fabricação do etanol, e o outro favorecia o rendimento energético, sendo a gasolina, o combustível que libera mais energia. Portanto, os alunos tiveram que resolver qual combustível deveriam utilizar para chegar ao final do jogo didático. Em um dos comentários um dos alunos afirmou que

\section{"[...] o jogo ajudou a escolher o melhor tipo de combustível" (A8).}

Assim, o jogo didático "Na trilha dos Combustíveis" permitiu que os alunos refletissem sobre uma forma de solucionar este problema da escolha do melhor combustível (aquele que favorece a sustentabilidade energética) e ainda buscou incentivar o educando a colocar em ação as suas ideias, contribuindo assim com a sociedade em que vive.

Segundo a literatura os jogos didáticos podem ser usados para apresentar obstáculos e desafios a serem vencidos como forma de fazer com que o educando atue em sua realidade. Segundo Ramos (1990) o desafio é algo que também pode despertar o interesse. O jogo didático desenvolvido trouxe um desafio ou um problema em que o aluno deveria traçar uma estratégia com intuito de resolver o mesmo. Dessa forma, o jogo didático é uma boa alternativa para que o aluno explore e construa o conhecimento químico de uma forma prazerosa e crítica.

Kishimoto (1996) alerta que o jogo didático deve possuir tanto a função lúdica (que está relacionada ao caráter de diversão e prazer que o jogo propicia), quanto a função educativa (que se refere à apreensão de conhecimentos, habilidades e saberes). Através da observação e da analise dos dados coletados no questionário percebeu-se que o jogo didático cumpriu com suas funções, tanto lúdica quanto educativa, ou seja, o jogo didático foi capaz de motivar o aluno a (re)construir conhecimento efetivo e de forma divertida.

Além disso, a atividade permitiu que os alunos desenvolvessem baseados em situações reais. Sendo assim, o aluno pôde-se colocar no lugar de um motorista e optar pelo uso de um combustível baseado nos conhecimentos químicos (rendimento energético e poluição atmosférica) construídos durante as aulas expositivo/dialogadas.

$\mathrm{Na}$ trilha os alunos eram questionados sobre o aprendizado construído durante as aulas expositivo/dialogadas, ministradas. Responder à pergunta de forma correta era uma condição para que o aluno não ficasse uma rodada sem jogar; para não ficar de fora do jogo o aluno parava e refletia sobre aquela questão traçando uma estratégia para continuar jogando. Pôde-se observar que se o aluno não sabia ou respondia à questão de forma incorreta o grupo parava e discutia a mesma. E, se ainda assim não chegassem a uma resposta aceitável, chamavam uma das pibidianas para dirimir a dúvida. Esta retomava a discussão com todo o grupo, os alunos apresentavam as suas ideias sobre a resposta da questão, ou seja, então usava da mediação do conhecimento para que o grupo chegasse a uma conclusão sobre a resposta da pergunta, minimizando assim os erros conceituais dos alunos. O que possibilitou a criação de um espaço de reflexão e discussão sobre a temática abordada.

Vale ressaltar que as perguntas não estavam presentes no jogo com o objetivo de que o aluno memorizasse o conceito químico/social, mas para que o mesmo refletisse sobre a questão e construísse a sua própria resposta, além de dirimir as dúvidas ainda remanescentes das aulas. Tinham ainda o objetivo de familiarizar o aluno com a linguagem química.

\section{A aceitabilidade do jogo e as funções lúdica e educativa}


Através das respostas do questionário percebeu-se uma boa aceitação do jogo didático "Na Trilha dos Combustíveis" pelos alunos. Bertoldi (2003) apresenta uma explicação para a grande aceitação do jogo didático, pois acredita que os jogos didáticos possibilitam o aprendizado de forma prazerosa, num contexto desvinculado da situação de aprendizagem formal. Mas acreditamos que para além da aceitação dos alunos por uma aula diferenciada que sai da rotina tradicional de explicação de conteúdo e resolução de exercícios a atividade desenvolvida deve ter um objetivo que se relacione com o desenvolvimento cognitivo do aluno. E no caso específico do recurso que tratamos neste artigo que relacione a diversão com o aprendizado do conhecimento científico.

Através da análise das justificativas dos alunos pôde-se observar que os educandos gostaram do jogo porque este promoveu diversão e aprendizado ao mesmo tempo, como pode ser observado no depoimento de alguns alunos:

"[...] o jogo proporciona aprendizado e divertimento ao mesmo tempo" (A12); "[...] o jogo contribuiu para a fixação do aprendizado" (A6); "[...] com o jogo a gente fica mais atento e aprende mais" $\left(A_{3}\right)$.

"[...] o jogo me proporcionou um momento de descontração" (Азо).

Estes relatos confirmam mais uma vez que o jogo didático cumpriu com sua função lúdica/educativa. Sendo assim, o equilíbrio entre a função lúdica e educativa permitiu que o jogo didático atingisse o seu objetivo e fosse um recurso didático capaz de motivar o aluno a (re)construir conhecimento de forma divertida. Segundo Murcia (2005) as características do jogo didático permitem que ele seja um veículo de ensino/aprendizagem e comunicação ideal para o desenvolvimento da personalidade e da inteligência dos alunos. Divertir-se enquanto aprende e envolver-se com a aprendizagem faz com que o aluno cresça, mude e participe ativamente do processo educativo, tornando-se assim sujeito ativo e crítico. Vale destacar também que ao responderem a esta questão os alunos citaram o aprendizado que construíram sobre sustentabilidade:

“[...] o jogo ajuda a gente a escolher o combustível mais sustentável” (A28);

"[...] o jogo ajuda a dar ideias de como ser mais sustentável" (A35);

"[...] o jogo me ajudou a construir conhecimento químico e a ser mais sustentável” (A2).

Estas respostas corroboram com um dos objetivos tanto do Projeto Temático quanto o do jogo didático "Na Trilha dos Combustíveis", qual seja, incentivar os alunos a levarem a sustentabilidade para a sua vivência e usar da mesma para garantir o futuro das próximas gerações e uma melhor qualidade de vida as mesmas.

Vale destacar a resposta de um aluno em uma das questões do questionário:

"[...] Nas respostas erradas, podemos pensar e ver o que écerto, assim aprendemos mais" (A17).

Através da afirmação deste aluno podemos observar claramente que o jogo didático é livre de pressões e que o aluno não tem medo de errar na hora de responder. Além disso, este aluno está aprendendo com os seus erros, está refletindo e chegando à resposta correta por si mesmo. Assim, está se tornando sujeito autônomo na construção do seu conhecimento, um aspecto muito importante e que foi proporcionado pelo jogo didático. Segundo Kishimoto (1996, p. 21): 
O jogo favorece o aprendizado pelo erro e estimula a exploração e resolução de problemas, pois, como é livre de pressões e avaliações cria um clima adequado para a investigação e a busca de soluções. O benefício do jogo está nessa possibilidade de estimular a exploração em busca de resposta e em não se constranger quando se erra.

Portanto, percebe-se que a ausência de pressão proporcionada pelo jogo permitiu uma reflexão rica para os alunos que os conduziu a um aprendizado efetivo. Perguntou-se ainda aos alunos se o jogo didático "Na Trilha dos Combustíveis" foi divertido; muitos dos alunos responderam que sim, por meio da justificativa de que o jogo proporcionou uma aula diferente, que saiu da rotina das aulas tradicionais. Vemos que os alunos se sentem motivados quando o professor traz para a sala de aula uma atividade diferente; os alunos se interessam e participam mais da aula. Isto nos faz crer que trabalhar com recursos diversificados promove o aprendizado e incentiva os alunos a participarem mais da atividade proposta.

\section{Impactos positivos do uso de jogos didáticos no Ensino e na formação cidadã}

O jogo dentro de uma sala de aula promove um ambiente de prazer, de livre exploração, um momento de construção de conhecimento e também um momento de real interação entre colegas e professores. Os alunos citaram em suas respostas que o jogo desenvolvido propiciou uma maior interação com os colegas. Recursos como os jogos didáticos permitem essa maior interação aluno/aluno, pois em sua maioria os jogos são praticados em grupos e promove competição, o que gera essa maior interação entre os alunos. Esta interação é muito favorável para o crescimento do aluno como pessoa e como cidadão, pois ele estará aprendendo a lidar com as diferenças existentes entre as pessoas, a se socializar, o que é importante para a sua vida em sociedade.

A competição também foi promovida pelo jogo; pôde-se observar isso através das atitudes dos alunos jogando; eles queriam ganhar e faziam o possível para isto acontecer. Alguns inclusive traçavam estratégias para lançar os dados e tirar um número alto e andar várias casas. Percebeu-se que aqueles alunos que antes se mostraram desinteressados nas aulas expositivo/dialogadas buscaram responder às questões de forma correta para não ficar sem jogar.

Vale destacar que o objetivo não era o de promover a competição entre os alunos, mas pôdese perceber que isto acabou promovendo mais ludicidade e interação entre os alunos do grupo enquanto jogavam, trazendo como consequência a (re)construção do conhecimento de forma prazerosa. Observou-se durante a aplicação da atividade que os alunos adquiriram uma posição mais ativa, pois questionavam muito mais que nas aulas cotidianas, o que vem reforçar mais uma vez que recurso desenvolvido possui caráter educativo.

Observou-se que a maioria dos alunos se envolveu na atividade lúdica proposta; até mesmo os que já haviam saído do jogo davam sugestões para os colegas que permaneciam jogando. Não se observou dispersão por parte dos alunos e nem desinteresse, o que normalmente ocorre em uma aula normal. Pôde-se observar ainda que durante o jogo os alunos riram, conversaram, brincaram, ou seja, os alunos se divertiram jogando. Mas, além da diversão, os alunos pensaram, trocaram ideias, agiram, aprenderam e se desenvolveram cognitivamente e socialmente.

Assim, por meio das observações realizadas em sala de aula durante a aplicação do jogo e da análise das respostas obtidas nos questionários, pôde-se perceber que os objetivos foram atingidos, $o$ de tornar a aula de Química mais dinâmica e interativa e contribuiu para o processo de ensino e aprendizagem dos conteúdos de Termoquímica envolvidos com a temática trabalhada (Rendimento Energético x Poluição) como pode ser observado pelo relato a seguir:

"[...] Achei o jogo interessante, e sem contar que reforçou o meu conhecimento" (A22);

“[...] além de ser divertido, revisa o conteúdo estudado” (A31). 
Estimulou-se nos alunos a reflexão, e tornou os sujeitos ativos na (re)construção do seu conhecimento e cidadãos críticos e atuantes na sociedade da qual fazem parte, como se pode depreender das falas citadas acima. O cidadão (aluno) precisa estar interligado tanto com a informação química quanto com o contexto social para participar ativamente da sociedade, ou seja, é necessário que o aluno compreenda a Química e relacione a mesma com a sociedade em que vive para poder participar ativamente desta.

A partir da análise dos resultados obtidos pôde-se perceber que o jogo didático "Na Trilha dos Combustíveis" atingiu um dos seus principais objetivos, o de recordar/revisar os conteúdos químicos relacionados à Termoquímica como, por exemplo, a variação de entalpia que permite verificar a quantidade de energia que é liberada pela reação de combustão sofrida pelos combustíveis e a partir disto determinar qual combustível rende mais (libera mais energia em sua reação de combustão) e também os conceitos relacionados aos recursos energéticos (escassez energética) como o que é um combustível, quais os tipos de combustíveis e a poluição liberada pela reação de combustão. A ressignificação de conceitos observada durante o desenvolvimento doa atividade vem corroborar que a ferramenta didática empregada melhora os processos de ensino e aprendizagem.

Há ainda que se frisar que o lúdico se constituiu num recurso diferenciado e relevante para tratar da temática abordada (Combustíveis e Impactos Ambientais), pois o mesmo se caracterizou por uma ação pedagógica que viabilizou situações de aprendizagem, pois os jogadores aprenderam errando e discutindo o seu erro com o docente mediador e com os demais alunos e ainda foram estimulados a resolver um problema como, por exemplo, qual combustível favorece a sustentabilidade energética. Assim o aluno foi estimulado a traçar uma estratégia para vencer o jogo e a partir desta estratégia pôde explorar investigar e interagir com o conceito químico de forma a compreendê-lo e assim (re)construir conhecimento significativo.

Vale destacar que o jogo complementou as atividades do projeto, ou seja, este recurso veio para reforçar com os alunos os conceitos químico/sociais trabalhados, pois muito conhecimento foi desenvolvido durante o jogo. O jogo serviu principalmente para reforçar o objetivo central do Projeto Temático denominado "Química e Energia em prol de um desenvolvimento sustentável" que era promover a mudança de atitude dos alunos, ou seja, desenvolver nestes uma consciência sustentável e uma postura de cidadãos atuantes na sociedade em que vivem.

\section{Os jogos didáticos e a formação inicial docente}

A formação inicial é de suma importância para o futuro docente, pois a mesma apresenta os principais pressupostos formativos para desempenho da sua atividade profissional. Sem uma formação inicial consistente, o docente não estará devidamente preparado para o enfrentamento de situações complexas, sejam elas nos aspectos teóricos e/ou didático pedagógicos no ensino de Química. Ou seja, a partir de uma formação inicial de qualidade o futuro docente constrói conhecimento adequado para a sua prática docente.

Nóvoa (1997) corrobora com essa ideia quando afirma que é necessária a prática nos cursos de formação de professores e a inclusão na rotina profissional (sala de aula) de hábitos de discussões e de reflexões sobre os acontecimentos e fenômenos sociais, históricos e sociais dos indivíduos envolvidos no processo (alunos). Ou seja, para garantir uma formação inicial baseada nas mudanças que a educação exige, é primordial que o futuro professor vivencie uma prática diferente em sala de aula. Esta prática gera muitas vezes insegurança entre os licenciandos em formação, uma vez que requer revisão de propósitos, valores e procedimentos vivenciados.

Vale assim destacar a experiência adquirida pelas pibidianas através da elaboração/desenvolvimento/aplicação/avaliação do jogo didático "Na trilha dos Combustíveis" durante a sua formação inicial. Esta experiência está relacionada principalmente ao uso da mediação para o desenvolvimento deste recurso, pois para o lúdico surtir efeito e promover a construção/reconstrução de conhecimento deve ser trabalhado de forma adequada e associar as funções educativa e lúdica. 
Segundo Santana (2012) o lúdico é um importante instrumento de trabalho para a elaboração do conhecimento. Para ser mediador do conhecimento o professor precisa saber lidar com os erros, estimular a aprendizagem, ajudar os alunos a se organizarem, educar através do ensino, dentre outros. Segundo Cunha (2012) durante o jogo didático o professor tem a oportunidade de verificar quais foram os caminhos utilizados pelo estudante, debater com a turma outras formas de resolução de problemas e apresentar, quando necessário, os procedimentos e modelos formais. Nesta concepção, o professor assume o papel daquele que conduz, estimula e avalia a aprendizagem do estudante. Ou seja, através do desenvolvimento do jogo didático citado, as pibidianas construíram a capacidade de serem professoras mediadoras no ensino de Química.

A elaboração e o desenvolvimento do jogo didático "Na trilha dos Combustíveis" foi uma excelente experiência para a formação inicial docente. Estas vivenciaram uma prática diferente baseada na superação do ensino tradicional a partir da inserção de recursos didáticos diferenciados na rotina escolar dos alunos e a partir destas experiências puderam observar que uma atividade lúdica como um jogo motiva o aluno a buscar seu aprendizado e torna as aulas mais prazerosas, permitindo que o aluno fique mais a vontade de expor a sua opinião e a sanar dúvidas. Assim após a reflexão realizada posteriormente a aplicação do jogo didático, acredita-se que este é um recurso que deveria fazer parte do processo educacional dos educandos. Salienta-se que este foi elaborado a partir de uma situação problema, o que garante que o interesse dos alunos pelo recurso será ainda maior.

\section{CONCLUSÕES}

A utilização de jogos didáticos vem crescendo nos últimos anos. Este recurso foge do modelo tradicional de ensino baseado na transmissão/recepção do conteúdo (modelo da racionalidade técnica, baseado na transmissão do conhecimento ao aluno e na memorização de fórmulas e nomenclaturas), sendo o professor é o detentor do conhecimento e o aluno é a tábula rasa que apenas absorve este conhecimento.

Estes possibilitam que os alunos vivenciem uma aula diferenciada. A vivência deste recurso não é apenas um momento de descontração para o aluno; é um momento em que este é motivado a buscar o seu conhecimento e desta forma se familiarizar com o mesmo. Possibilitando ainda que o aluno seja autônomo e possa alcançar um aprendizado efetivo.

No jogo "Na trilha dos Combustíveis" o aluno passou a ser autônomo quando foi estimulado a traçar uma estratégia para ganhar o jogo; esta estratégia estava relacionada com uma forma de responder aos questionamentos e a partir disto o mesmo pôde (re)construir conhecimento. Quando os educandos aprendem brincando demonstram alegria e prazer em aprender. Assim, percebe-se que este recurso tornou a aula de Química mais dinâmica e interativa e aproximou a Química dos educandos e de seu cotidiano. Durante o jogo o aluno teve um contato direto com pessoas, aprendeu, a comunicar-se e, principalmente, a aceitar as ideias e a diversidade existente entre as pessoas.

No momento em que este jogo didático foi aplicado em sala de aula pôde-se observar uma maior interação entre aluno/aluno e, ainda, que a interação aluno/professor foi estreitada, pois a atividade lúdica deixou o educando mais a vontade para dirimir suas dúvidas, conforme observado e relatado pelos discentes. Permitiu que o conhecimento apreendido pelos educandos fosse recordou/revisou e ainda promoveu a apropriação de um novo aprendizado. Esta pôde ser observada principalmente no momento em que os alunos respondiam aos questionamentos necessários para não ficar uma rodada sem jogar.

Por fim, acredita-se que a diversificação nos recursos didáticos e a inserção de atividades lúdicas como os jogos didáticos, podem sim tornar os conteúdos químicos mais proveitosos e até tornar esta disciplina mais interessante e bem vista entre os educandos, pois estes irão aprender de uma forma prazerosa, interativa e sem cobranças. O ensino de Química deve contribuir para a formação de cidadãos e, dessa forma, deve permitir o desenvolvimento de conhecimentos e valores que possam servir como instrumentos mediadores da interação do indivíduo com o mundo. Percebeu- 
se através deste trabalho que se consegue isso mais efetivamente implementando atividades lúdicas no processo de ensino e aprendizagem.

\section{REFERÊNCIAS}

ALMEIDA, A. M. Papel do trabalho experimental na Educação em Ciências. Revista Comunicar Ciência, Lisboa, Ano I, nำ, pag. 4-5, Outubro/ Dezembro, 1998.

BERTOLDI, M. A. A escolha dos jogos definida pelas dificuldades especificas de cada criança. Curitiba, 2003.

BRASIL, MEC. LDB-Lei de Diretrizes e Bases da Educação Nacional. Lei no 9.394, de 20 de dezembro de 1996. D.O.U de 23 de Dezembro de 1996.

BRASIL. MEC. Secretaria de Educação Média e Tecnológica. Parâmetros curriculares nacionais: ensino médio. Brasília, 1999. 394p.

BRASIL. MEC. PCN+ Ensino Médio: Orientações Educacionais Complementares aos Parâmetros Curriculares Nacionais. Ciências da Natureza, Matemática e suas Tecnologias. Brasília: MEC/Semtec, 2002.

CAVALCANTI, E. L. D.; SOARES, M. H. F. B. O RPG como estratégia de problematização e avaliação do conhecimento químico. Revista Electrónica de Enseñanza de las Ciencias, v 8, p. 255 - 280, fev/março, 2009.

CHAER, G.; DINIZ, R. R. P.; RIBEIRO, E. A. A Técnica do questionário na pesquisa educacional. Evidência, Araxá, v.7, n.7, p.251-266, 2011.

CUNHA, M. B. Jogos no Ensino de Química: considerações teóricas para a sua utilização em sala de aula. Química Nova na Escola. Vol. 34, oㅡ 2, p. 92-98, 2012.

DULFES, C. O jogo de Pascal a Schuiller, Porto Alegre: ART Med Editora, 1997.

FIALHO, N. Os Jogos Pedagógicos como Ferramentas de Ensino. In: Congresso Nacional de Educação e Congresso Ibero-Americano de Violência nas Escolas, v. 3, Anais... Curitiba, 2008.

GODOY, A. S. Introdução à pesquisa e suas possibilidades. Revista Administração de Empresas - ERA, v. 35, no 32, p. 57-63, 1995 .

GRANDO, R. C. O Jogo e suas Possibilidades Metodológicas no Processo de Ensino-Aprendizagem da Matemática. Dissertação (Mestrado em Educação, subárea: Matemática). UNICAMP, Campinas, 1995.

KISHIMOTO. T. M. O Jogo e a Educação Infantil. In: Jogo, Brinquedo, Brincadeira e a Educação.

KISHIMOTO, T. M. (org.). São Paulo: Cortez Editora, 1996.

LAVILLE, C.; DIONNE, J. A construção do saber: manual de metodologia de pesquisa em ciências humanas. Porto Alegre: Artmed, 1999.

LEGRAND, L. Psicologia Aplicada à educação Intelectual. Rio de Janeiro: Zahar Editores, 1974.

MORAES, R. Uma tempestade de luz: a compreensão possibilitada pela análise textual discursiva. Ciência \& Educação, Bauru, SP, v. 9, n. 2, p. 191-210, 2007.

MURCIA, J. A. M., (org.). Aprendizagem Através do Jogo. Trad. Valério Campos. Porto Alegre: Artmed, 2005. NÓVOA, A. Formação de professores e profissão docente. In: NÓVOA, A. (Coord.). Os professores e sua formação. 3. ed. Lisboa: Dom Quixote, 1997.

RAMOS, E. M. F. Brinquedos e jogos no ensino de Física. Dissertação (Mestrado em Ensino de Ciências), Universidade de São Paulo, São Paulo, 1990. 
RIZZO, G. Jogos inteligentes: a construção do raciocínio na escola natural. zed. Rio de Janeiro: Bertrand Brasil, 2001.

SANTANA, E. M. O Uso do Jogo Autódromo Alquímico como mediador da aprendizagem no Ensino de Química. São Paulo. Dissertação (Mestrado Instituto de Física, Instituto de Química, Instituto de Biociências) Faculdade de Educação, Universidade de São Paulo, São Paulo, 2012.

SOARES, M. H. F. B.; OKUMURA, F.; CAVALHEIRO, T. G. Proposta de um jogo didático para ensino do conceito de equilíbrio químico. Química Nova na Escola, n. 18, p. 13-17, nov. 2003.

SOARES, M. H. F. B. Jogos e Atividades Lúdicas no Ensino de Química: Teoria, Métodos e Aplicações In: XIV Encontro Nacional de Ensino de Química (XIV ENEQ), Anais... Curitiba - Paraná, 2008.

SOARES, M. H. F. B. Jogos e Atividades Lúdicas para o Ensino de Química. Goiânia - GO: Editora Kelps, 2013.

VALENTE, J. A. Ação afirmativa, relações raciais e educação básica. Revista Brasileira de Educação, São Paulo, n. 28, p. 62- 76. Jan./abr, 2005.

VYGOTSKY, L. S. A formação social da mente. São Paulo: Martins Fontes, 1989.

Fernanda Welter Adams: Licenciada em Química e Mestre em Educação pela Universidade Federal de Goiás - Regional Catalão.

E-mail: adamswfernanda@gmail.com

Simara Maria Tavares Nunes: Licenciada (1995) e Bacharel (2002) em Química, Mestre (1999) e Doutora em Ciências (2003) - Área de Concentração Química - pela Faculdade de Filosofia Ciências e Letras de Ribeirão Preto da Universidade de São Paulo. Atualmente é Professora Associada da UAE de Educação da Universidade Federal de Catalão, na área de Ensino de Química.

E-mail:simarasn@gmail.com 